\title{
Practices to obtain lice counts at Norwegian salmon farms: status and possible implications for representativity
}

\author{
Trine Thorvaldsen*, Kevin Frank, Leif Magne Sunde \\ SINTEF Ocean, Postboks 4762 Torgarden, 7465 Trondheim, Norway
}

\begin{abstract}
The Norwegian aquaculture industry faces several challenges. One such challenge is the prevalence of salmon lice, which adversely affect both wild and farmed salmon. At the core of the current regulatory regime are mandatory lice counts that are manually obtained from fish farms. Thus, the objective of this article was to present knowledge regarding counting practices, fish farm employees' perceptions of the strengths and weaknesses of these practices, and possible implications for representativity. Interviews comprised the main method of data collection for this research. The results addressed 3 phases of the lice-counting process: sampling, sedation, and counting. The organizational factors that may influence counting, such as training, time, and manning, are also described. Our results show variations in the choice of equipment used for different stages of the lice-counting process, including sampling and crowding time. In the interviews, employees discussed the challenges inherent in identifying different lice species and the associated developmental stages of the lice. The findings presented in this paper demonstrate the importance of documenting actual practices at the fish farms in order to optimize lice counts and should be considered by the aquaculture industry, technology developers, and industry regulators in the future.
\end{abstract}

KEY WORDS: Salmon farming $\cdot$ Sea lice $\cdot$ Salmon lice $\cdot$ Lice counts

\section{INTRODUCTION}

The Norwegian aquaculture industry is a leading producer and exporter of farmed Atlantic salmon Salmo salar, providing employment to people in rural areas and within supplier industries. However, the industry faces numerous challenges, such as securing feasible sea-based production sites in coastal areas, ensuring the welfare of fish, and dealing with environmental interaction issues related to the escape of farmed fish and the extent of salmon lice affecting wild Atlantic salmon (Torrissen et al. 2013, Forseth et al. 2017).

Common lice species in Norwegian salmon include Lepeophtheirus salmonis (salmon louse) and Caligus

\footnotetext{
*Corresponding author: trine.thorvaldsen@sintef.no
}

elongatus. Salmon lice adversely affect both wild and farmed salmon by reducing their rate of growth and eventually killing the infected fish (Finstad \& Bjørn 2011, Forseth et al. 2017). Salmon lice pose numerous challenges to their hosts; they usually gather at open net-pen salmon farms, where they multiply at a significant rate (Torrissen et al. 2013). Regulations related to lice management introduced by Norwegian public authorities aim to reduce the negative effects of sea lice on wild salmon stocks and ensure the ethical and efficient production of farmed salmon. Consequently, the task of controlling infestations of salmon lice is of high priority for the aquaculture industry; however, this demands extensive resources for monitoring and preventing lice infil-

() The authors 2019. Open Access under Creative Commons by Attribution Licence. Use, distribution and reproduction are unrestricted. Authors and original publication must be credited. 
trations as well as delousing infected salmon (Liu \& Bjelland 2014). The economic loss from lice infestations and treatments may be up to $13 \%$ of revenues in some parts of Norway (Abolofia et al. 2017). Furthermore, lice management activities, such as delousing, may also have negative effects on the welfare of farmed salmon, as it has been found to be stressful for the fish (Føre et al. 2018).

The production volumes of salmon farming in Norway are regulated through a licensing system based on maximum total biomass (MTB), which was introduced in 2005. MTB defines how much fish a company may have at sea and is regulated at both the company and locality level. Furthermore, national regulations for aquaculture production state that the number of fish per production unit (net cage) should not exceed 200000.

Criticism of the aquaculture industry's handling of the issue of salmon lice has influenced the operation of licenses and the regulations imposed on the industry (Jackson et al. 2018). In 2009, a more rigorous protocol (Anon 2009) was introduced by the Norwegian Food Safety Authority (NFSA). Since 2017, salmon lice have represented a key indicator for sustainability and growth in the regime of production management in the aquaculture industry. In this 'traffic light system', the extent of the prevalence of salmon lice determines whether production should be decreased (red area), maintained (yellow area), or increased (green area) in each of 13 production zones. In this system, in order for production to increase, the average number of lice in a zone should not exceed 0.5 mature female lice fish ${ }^{-1}$. The NFSA monitors lice numbers and performs regular inspections to ensure the fish farmers' compliance with regulations.

Predictability for fish farmers related to which criteria will determine further expansion and growth as well as a collective responsibility to uphold environmental standards in each zone is the basis of the production management regime (Hersoug et al. 2019). Although the fish farms in each zone are evaluated collectively, farms that stay below 0.1 mature female lice per fish may apply to increase their MTB, regardless of the status (red, yellow or green) of the zone in which they are located. In addition to national regulations, regulating the number of salmon lice is also important for obtaining environmental certifications, such as the Aquaculture Stewardship Council standard (ASC). Many salmon companies hope to obtain this standard to improve sales through access to certain markets (Amundsen \& Osmundsen 2018). In the ASC standard, the limit is 0.1 mature female lice per farmed fish, and certified farms have to make these counts publicly accessible.

Mandatory requirements state that salmon lice counts must be reported weekly to the NFSA (Anon 2012). If sea temperatures are below $4^{\circ} \mathrm{C}$, numbers may be reported every fortnight. The number of fish included in the lice count depends on the geographical location of the sites as well as the time of year. While these requirements leave room for different methods of counting and different types of equipment, they do state that fish samples should be acquired by crowding nets or through another method that ensures a representative selection of fish. In fish farms with more than 3 net cages or production units, at least half of the cages should be sampled each week to ensure that all cages are reported after 2 counts. Furthermore, the fish should be sedated before they are counted for lice. When the lice are being counted, each fish should be thoroughly examined one at a time, and any lice that fall into the container used for sedation should also be included in the count. There are 3 life stages of salmon lice that must be counted, categorized, and reported: (1) mature females, (2) moving stages, and (3) fixed stages. The life cycle of salmon lice comprises 8 developmental stages: nauplius 1, nauplius 2, copepodid, chalimus 1, chalimus 2, pre-adult 1, pre-adult 2, and adult (Hamre et al. 2013). According to the requirements, fish farmers must report the incidence of mobile (i.e. pre-adult forms and mature females) and fixed stages (i.e. chalimus 1 and chalimus 2).

The manual counting of lice at each fish farm is essential to the current regulatory regime, and the results of these counts are publicly available (https:// www.barentswatch.no/fiskehelse/). A high-profile case from 2015 illustrates the potential consequences of non-compliance with these regulations. An operational manager at a Norwegian fish farm, with $20 \mathrm{yr}$ experience in the fisheries and aquaculture industries, was brought to court and pleaded guilty to reporting incorrect lice numbers to the NFSA: between 2012 and 2013, lice numbers on the farm were 15 times higher than the regulated amount. The man was sentenced to 6 mo in prison, and the company he worked for was fined 5 million NOK (Dagens Næringsliv 2018).

In addition to fulfilling regulatory purposes, lice counts may also provide important data that can be used in infestation models and simulations as well as for policy advice (Revie et al. 2007, Helgesen \& Kristoffersen 2018). Lice counts provide data that can be used to evaluate the effect of lice-reducing meas- 
ures; they also provide deeper insights into the interactions between salmon lice and salmon populations (Gautam et al. 2017).

Internal procedures in the companies are used to ensure that lice counts are performed according to the formal requirements. While the requirements call for a representative selection of fish, they do not include any specific criteria for representativity. Because of this, methods and practices may therefore vary. A common approach to estimate the prevalence of sea lice infestations is to inspect a random sample of fish (Heuch et al. 2011), meaning that questions of representativity, sample size, and selection bias (i.e. the ability of a sample to represent the population) arise. Lice counts are reported per locality, but the variation in the number of lice per fish is often greater between cages than within a cage (Revie et al. 2005, 2007). Regarding representativity, because the counting and categorizing of lice is carried out by humans, the objectivity of the results is also relevant. Previous studies have addressed questions of how the counters may affect the results as well as the influence of environmental conditions (such as light and wind) on employee performance (Heuch et al. 2011, Elmoslemany et al. 2013, Gjerde et al. 2016).

Despite the importance of lice counts for the regulatory regime of the Norwegian aquaculture industry, research-based knowledge regarding how the counts are obtained and their possible implications for representativity is limited (Thorvaldsen et al. 2018). Thus, the objective of this article was to provide an overview of current practices for counting lice, employees' perceptions of the strengths and weaknesses of these practices, and the implications of the findings for the representativity of lice counts reported from fish farms. Two research questions were asked: (1) what are the practices in place for obtaining lice counts at a selection of Norwegian fish farms, and (2) what are employees' perceptions of these practices? Based on the findings from these research questions, implications related to the representativity of lice counts are discussed. Our results are expected to be of value for fish farmers, technology developers, and regulators of the industry, providing knowledge that may assist combined and individual efforts to ensure optimal methods of sustainable salmon production.

\section{MATERIALS AND METHODS}

In order to gather information about the practices and perceptions of employees, 17 qualitative semi- structured interviews with 18 informants were conducted. Semi-structured interviews are based on an interview guide, which is comprised of a list of questions or topics of interest (Bernard 2006). The interview guide was prepared by the authors and finalized after receiving input from other researchers in the project team and a group of industry representatives. Open-ended questions were used to allow the participants to elaborate on topics they found particularly relevant. The relevant occupational health and safety issues for personnel were also discussed. The questions were related to the following 3 topics: (1) the equipment and methods used in the 3 stages of obtaining a lice count (i.e. catching the fish, sedating the fish prior to counting, and the counting process itself); (2) participants' perceptions of lice counting (i.e. description of practices used to count lice, the practices that work well, and areas that require improvement); and (3) participants' background, training, and procedures (i.e. extent of their experience in the industry, the training provided for those involved in the process, and the lice-counting procedures used within each participant's company). To explore the participants' perceptions of the topics mentioned above, numerous questions were posed to them, including 'What aspects of lice-counting do you think may affect how thorough it is?' and 'Do you think you and your colleagues would get the same result as each other if you counted lice on the same fish?'

The participants for this study were selected from employees who regularly conduct lice counts or have thorough knowledge of current practices. The recruitment of the participants ensured variation in company affiliation as well as in the geographical location of the fish farms. The participants were recruited through industry contacts who provided their contact details. Participation was voluntary, and anonymity was ensured in the publication of the results of the interviews.

All of the interviews, apart from one, were conducted over the phone in autumn 2017. One researcher conducted all the interviews, and each interview lasted between 20 and $50 \mathrm{~min}$. The final interview was a group interview consisting of 2 participants and the researcher. This interview was performed in person at the land base of a fish farm. The interviews were scheduled, and the participants were given the main topic and intention of the interviews beforehand. The list of interview questions was not provided in advance.

The participants were employed at 1 of 8 aquaculture companies. The companies varied in size; some 
had just 1 salmon production license, while others were multinational companies (Table 1). The 18 participants consisted of operational personnel (fish farmers), assistant operational managers, and operational managers overseeing the production at 1 or more fish farms. The selected participants had between 2 and 30 yr experience in the aquaculture industry, and they were selected from 9 Norwegian counties (Fig. 1). One of the fish farms where participants worked utilized steel cages; the others used net cages with plastic collars.

The interview data were analyzed by comparing the participants' answers and summarizing the findings. The findings were grouped according to the 3 different phases of the lice counting operation - sampling, sedation, and counting. Some organizational aspects and challenges related to health and safety were also questioned, so that a holistic overview of the current practices could be presented. The quotes presented in this paper were translated from Norwegian to English by the authors. In the text, the quotes are numbered according to the interview numbers presented in Table 1. The internal procedures from 4 of the 8 companies were also acquired to study variations in company procedures. The procedures of company $\mathrm{C}$ were compared with the interview data from employees of company $C_{\text {, }}$ thus providing insight into the relationship between company procedures and practices.

\section{RESULTS}

\subsection{Sampling}

Three equipment types were used for sampling fish: 7 fish farms used a crowding net, 5 used a dip net on a crane, and 2 used a smaller crowding net permanently installed in the net cage and attached to the net wall when not in use. Four informants utilized both the crowding net and the dip net, depending on the operational conditions (e.g. the size and depth of the fish). One participant stated that 'the smaller fish were afraid of the dip net' (No. 6). Another said that 'the dip net is easier to use than the crowding net when the fish are deeper in the water column' (No. 13). The participants estimated that they usually sampled fish from a depth of 5 to $10 \mathrm{~m}$. This depth var-
Table 1. List of participants from Norwegian salmon farms interviewed in 2017, sorted by company, position, and county

\begin{tabular}{|llll|}
\hline $\begin{array}{l}\text { Inter- } \\
\text { view no. }\end{array}$ & $\begin{array}{l}\text { Com- } \\
\text { pany }\end{array}$ & Position & County \\
\hline 1 & A & Operational manager & \\
2 & A & Fish farmer & Sør-Trøndelag \\
3 & B & Fish farmer & Troms \\
4 & B & Operational manager & Sør-Trøndelag \\
5 & C & Assistant operational manager & Møre og Romsdal \\
6 & C & Foreman & Møre og Romsdal \\
7 & C & Assistant operational manager & Hordaland \\
8 & C & Fish farmer & Hordaland \\
9 & C & Assistant operational manager & Troms \\
10 & C & Assistant operational manager & Møre og Romsdal \\
11 & D & Fish farmer & Rogaland \\
12 & D & Assistant operational manager & Rogaland \\
13 & D & Two operational managers & Finnmark \\
14 & E & Operational manager & Nord-Trøndelag \\
15 & F & Fish farmer & Nordland \\
16 & G & Operational manager & Hordaland \\
17 & H & Daily manager & Sogn og Fjordane \\
\hline
\end{tabular}

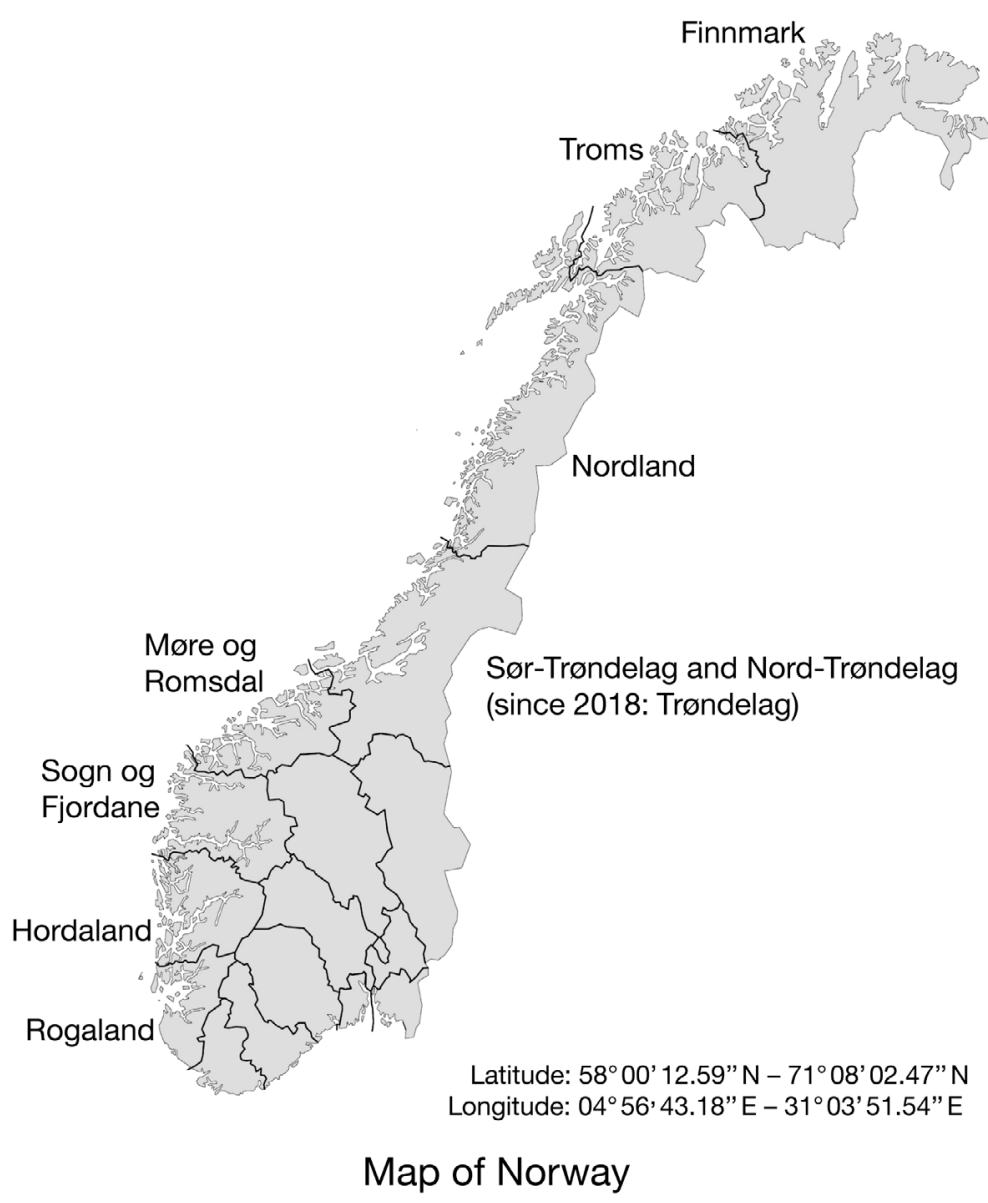

Fig. 1. Geographical location (counties) of the 8 Atlantic salmon fish farms where the interviewees worked (source: www.kartverket.no; altered version) 
ied according to the time of year and the position of the fish in the net cage.

All the fish farms represented in this study used feed to gather the fish in the sampling area of the cage. Sampling in the first cage usually began in the morning and typically took between $30 \mathrm{~s}$ and $10 \mathrm{~min}$ to complete. Five of the participants said that it was often challenging to catch enough fish for the sample and that sampling may take longer than normal if this is the case. They stated that it was difficult to catch fish later in the day, especially in winter, as it was often too dark.

Although regulations stipulate lice counting of at least 10 fish from June to January, all but one of the fish farms sampled 20 fish from each net cage on a weekly basis. When asked about company practices that ensured a representative selection of fish, the answers varied. Eight of the participants indicated that the samples were random. Regarding the number of fish to be sampled, one operational manager claimed that 20 fish 'will never be representative' (No. 13). Another participant believed the results would be the same regardless of whether 20 or 100 fish were sampled. He believed that the depth of water from which the sample of fish was taken was more important: 'further down, fewer lice' (No. 14). Another participant also said that there were more lice on the fish that were closest to the surface of the water. The time of day of sampling also arose as a topic: 'If we count early in the day on one site, and late in the day on another, we get different results' (No. 7). However, this participant did not elaborate on the causes of this difference.

The use of feed to gather fish prior to crowding was another factor related to representativity. One participant said this practice meant that samples often consisted of the hungriest fish (No. 4), while another participant commented that the bigger fish would be more likely to go for the food than the smaller fish: 'The big fish are more used to going for the food when they have the opportunity. The small fish do not realize that food is coming' (No. 3).

All the participants stated that the smallest fish with very poor growth rates were not included in the counting. However, another category-weak fish (i.e. those who were not growing as well as expected) - was included by 5 participants. One participant stated that 'We make sure to gather the sample slightly away from where the feed is given so that not just the strongest fish are sampled. We want some of the weak fish too, not only the strong fish. Weak fish may have more lice' (No. 15). Another participant said 'The sample is based on the situation in the cage. If we have a lot of weak fish, say $10 \%$, then we count some of the weak fish to reflect that' (No. 4).

Four of the participants explained how they sometimes performed additional 'control counts.' These control counts involved counting more fish than usual based on the impression that the sample is not representative. The decisions related to this were not made by employees at the fish farms but by the onshore management team. At all sites, after the fish were in the crowding net, they were moved to the sedation containers with a hand-held dip net. The number of fish moved at one time was dependent on how many fish there were. This moving, as well as the time spent on sedation and counting, affected the crowding time (i.e. the time the fish sample is gathered in the tightened crowding net or dip net). According to the participants, the time taken to crowd the fish can vary from 3 to $30 \mathrm{~min}$, depending on whether gill scouring is conducted. The average crowding time was 10 to $15 \mathrm{~min}$.

The crowding net is managed in a way that is gentle for the fish, thus ensuring their welfare and avoiding the loss of scales. Three of the participants said that crowding time and density may affect lice numbers, because having the fish in close contact may cause the lice to fall off them. One participant stated that 'We lower the dip net so that it's on the surface of the water. The fish may become stressed, but they are safe. My experience is that the fish that stay crowded in the net the longest have the least amount of lice' (No. 10).

\subsection{Sedation}

Two types of anesthesia were used for sedating the fish prior to counting lice: Benzoak and Finquel. The anesthetic is mixed according to instructions, but the mixing ratio may also be based on experience or advice from veterinarians. The anesthetic mixture is replaced throughout the sampling procedure. According to 1 of the 4 procedures studied, the water should be replaced after each sample. In case of larger samples in the same container, the water should be changed if it becomes murky. Two of the procedures recommended that the water should be changed when it gets murky, while the last procedure did not mention replacement of water. According to the participants, the containers used for sedation are usually between 300 and $600 \mathrm{l}$. Participants stated that they place 5 fish in a container at a time, but the number of fish may be adjusted based on the 
size of the fish and the size of the container. Related to sedation, one participant also explained that a common method of making sure that the fish are sufficiently sedated is by lifting the fish and ensuring that it does not flap its tail.

\subsection{Counting lice}

Participants were asked which type of equipment they use when counting lice. Ten of the participants stated that they hold the fish in their hands while they count the lice; 3 said that they use a table to lay the fish down on while counting, and the rest did not provide information on this question. The fish was either returned directly to the net cage after counting the lice or kept in a separate container containing seawater to ensure that it could recover before returning it to the net cage. Two informants had their sedation containers custom-built and integrated with the counting table. One counting table included a tube that was used to return the fish to the cage. This means that the fish cannot escape and also serves to make the fish less stressed. When the lice are counted, 12 of the employees stated that they wear gloves to avoid damaging the fish while the others did not specify if they wore gloves. One participant described the importance of wearing gloves: 'I like to wear disposable gloves so I can feel the fish with my hands. I feel if there is something that is not supposed to be there. The gloves usually used are too thick, I think' (No. 15).

The interviews highlighted that the task of categorizing lice in different stages and species is not without its challenges. The small fixed lice were mentioned by 9 participants as being the most difficult to detect. A quote from one of the participants illustrates some of the challenges involved in categorization: 'What we count are 'skottelus' (meaning Caligus elongatus): fixed, moving, and mature female lice. The skottelus are quite small and round. Fixed lice are also small and round, but they are different in color. To distinguish between the moving and fixed lice, you can use your finger to figure out if it moves. It's difficult to see the fixed lice. If you see a brown spot, it may be bleeding, for example. It may also be difficult to see lice on the back of the salmon, where it is dark and dark green' (No. 3).

In order to count the lice, employees need to be knowledgeable about the different life stages of the lice in terms of how they appear, where to look for them, and the appropriate techniques needed to locate and categorize them. Two of the participants said they use illustrations and pictures to help them if they are uncertain, and that they also ask each other for help so as to categorize the lice correctly.

Lice that fall off the fish into sedation containers should also be included in the count. According to 2 of the participants, the focus on counting lice in the sedation containers has increased in recent years. Different solutions exist in this regard, with the most common solutions being the use of a tarpaulin to catch lice that fall off in the container or counting the lice visible in the container. Some also use a filter or sieve to catch lice when the container water is drained. For the 8 participants who used a tarpaulin, 3 said it was white, one said it was green, and the rest did not specify the color. Four participants used a sieve, and one of them found this method somewhat flawed: 'We use a sieve to count lice in the container, but I guess $50 \%$ of the lice will be washed out, because it clogs from the mucus as the water is drained' (No. 12).

To identify conditions that may affect the counting, participants were asked if having the assistance of a colleague when counting lice would mean getting the same results. Ten of the 18 participants said that the results may vary in this regard. When asked why, the experiential level of those doing the counting was mentioned by 3 participants. One said that the biggest difference would be related to finding the smallest lice. Two participants thought that some colleagues were 'more thorough' than others when counting (No. 2, No. 10). Another said that 'No one can become an expert in counting lice. I can count 5, and you can count 6 . It will differ from person to person' (No. 3). Further to this subject, one participant said they asked their colleagues for assistance when they were not sure about something: 'Yes, I think we would get the same result 70 to $80 \%$ of the time, but the very smallest lice can be difficult. We ask each other' (No. 6).

Conditions such as the weather, light, and wind were acknowledged as having a possible impact on the counting results, but these conditions were not seen as extensive challenges. One participant said that bad weather may make the employees doing the counting speed up the process more than usual. Another participant said that sunlight was the worst condition, as it exhausted his eyes. One participant said that during certain periods of delousing, lice counting is also conducted at night using artificial light: 'Fixed lice can be hard to see. Especially at night' (No. 14). At times of low natural light, headlamps were used by 2 participants, but others said that the lights on the boats were sufficient. 


\subsection{Organizational aspects}

The interviews highlighted that the work conducted by the participants is also closely associated with various organizational aspects, including training, time and resources, and manning and the division of responsibility.

Employees that perform lice counts depend on proper training and guidance. A quote from one participant illustrates this: 'Before, we heard that the lice could be found on the belly, so we did not look on the back of the fish. But now, we do that. We attended a course where they told us that the lice may be on the back as well' (No. 12). On-the-job training, combined with formalized training, is the most common way for employees to learn how to conduct lice counts. At the farms, the operational manager will show and tell newcomers how the work is done. In addition, formalized training may consist of an exam, where employees must show that they can correctly identify the different stages and species of lice. It is also common practice to have a veterinarian conducting the counting with employees from time to time. Both veterinarians and fish biologists play a role in the aquaculture industry in keeping lice numbers low and ensuring the welfare of the fish. These professionals may either be directly employed by a company or hired through a service company.

The participants were asked about the time they spent counting lice. Their answers showed that differences exist between sites and shifts. When the participants were asked how long it would take to count 20 fish, the answers varied from 15 to $80 \mathrm{~min}$. The time spent counting depended on how quickly the fish were caught, how many employees participated, and the number of cages involved. Three participants said that they combined the counts with weighing and gill scores, whereas the others did not provide information on this. In general, half a day to a full day was commonly spent counting lice.

The participants were asked if they experienced time pressures, which may lead to reduced precision. Fourteen of the participants did not report this to be a problem and felt that they were given enough time to conduct their work in a thorough manner. However, during certain periods in the summer, with high lice numbers and frequent counts, other tasks could be neglected due to the time spent counting lice. One participant said 'We have counted a lot this summer due to high numbers of lice. It may affect other tasks that need to be done, when we have to count lice 3 times a week' (No. 12).
Costs associated with lice counts were perceived to be a bigger challenge than time pressure. One of the participants who worked on a site with steel cages claimed: 'We spend an unbelievable amount of time counting lice, and the cost is high. It is the average salary of 2 people one day each week' (No. 17). The same participant also argued that because the regulations require counts from each unit, employees at fish farms with many cages spend more time on this work. In comparison, fish farms with fewer but larger cages save time.

Questions were asked about manning and the division of responsibility. Lice counts are commonly conducted by 3 employees working together. Temporary workers may take part by writing down the results, while experienced workers with formal training find and categorize the lice. In some areas, external 'lice counting teams' travel from farm to farm to count lice. Three of the participants (No. 7, No. 11, and No. 16) said they regularly used external staff to count lice. These employees worked for 3 different companies: 2 of them worked at a fish farm in Hordaland, and one worked at a fish farm in Rogaland. One of them had an external team come in every second week, and the 2 others had a team come in once a month. The idea behind external teams is the provision of standardization and the avoidance of affiliation with certain companies. The participants who had teams come to their farms found it useful, but another participant found it unnecessary and argued that trust was more important: 'People do not trust their neighbor. We must get away from this. Regular inspections from the Food Safety Authority should be sufficient' (No. 17).

\subsection{Occupational health and safety concerns}

According to the participants, the workload while counting lice is particularly heavy during periods of frequent counting (more than once $\mathrm{wk}^{-1}$ ). One participant said that using a hand-held dip net to move fish from the net cage and into the container is difficult due its repetitive nature, especially when the salmon are heavier. To reduce this strain, employees at another fish farm use a small dip net attached to a crane on the working vessel. The participants also typically work in a stooped position, which may cause a strain on their backs. While counting lice, the fish are held in the hand of the person doing the counting or placed on a table. Consequently, bending the back is common. This was perceived as unfavorable. One participant said the tables used for 
counting were low, and because he did not want to lift the fish for fear of losing it, he had to work with his back bent.

\subsection{Variations in practice}

To conclude, the interviews highlighted that practices for obtaining lice counts varied among companies but also within companies, and in some cases, between different work shifts at the same fish farm. Variations related to the organization of the work included the number of employees involved in the work, whether the company used external counting teams, the type of formal training implemented for lice counting, and the time spent counting lice. In terms of sampling, there were different types of equipment used, and the crowding period, selection criteria, time of day for counting, and the depth of sampled fish all varied. In relation to anesthesia, the type of anesthetic, duration of sedation, and number of fish in the container varied. When counting and categorizing lice, the experiences of the participants and techniques they used also varied. Ten participants said that they held the fish in their hands, while 3 used counting tables. Furthermore, 2 said that they used tools such as headlights, while others did not. Twelve of the participants wore gloves to protect their hands and protect the scales on the fish. A separate container to allow the fish to recover after anesthesia and/or a solution for gently transferring the fish back into the cage was also used. The interviews also highlighted variations in the methods used for catching and counting lice that fell off during sedation.

\subsection{Comparing procedures and practices}

The internal procedures of 4 companies were studied to ascertain the differences between them. The level of detail regarding the execution of the work as well as the equipment needed varied. For instance, one procedure included recommendation of a separate recovery container and another of additional lights, whereas the rest did not. Two procedures also stated that weak fish should be included in the samples, whereas the other 2 did not mention this. To study the variations between procedures and practices, the internal procedures of company $\mathrm{C}$ were compared to answers supplied by 6 employees working for different fish farms in that company. This comparison identified variations between the procedure and the described practices.

Some examples of these variations were related to knowledge of the counters, sampling, and crowding time. The procedure stated that the employees responsible for obtaining lice counts must be able to distinguish between the lice stages. In the interviews, 5 out of 6 of the employees gave examples of the challenges associated with differentiating between the stages. Furthermore, according to the procedure, a sample of normal fish, representative of the population in the cage, should be sampled. In practice, all employees fed the fish before sampling (this was not mentioned in the procedure), and 2 of the 6 employees described the sampling as random. The procedure also stated that crowding time should be curtailed (to avoid lice falling off the fish) by immediately placing the crowded fish in a sedation container. In practice, the employees reported the crowding times as varying from 5 to $30 \mathrm{~min}$.

\section{DISCUSSION}

For lice counts to be used as a basis for regulating production growth and monitoring development of lice prevalence over time, they need to be representative. Variation in the practices of obtaining lice counts may also have implications for commensurability (e.g. comparison between farms). The interviews highlighted that several of the participants have their own opinions regarding the representativity of the lice counts. In this section, the findings related to sampling practices, crowding time, counting lice in the sedation container, the human factor, and objectivity are discussed. Considering the relevant literature, possible implications related to representativity are described.

\subsection{Sampling practices}

The requirements for lice management state that a representative sample of fish should be acquired, but no details regarding the criteria for a representative sample or any aspects that may affect the representativity are provided in the regulations (Anon 2012).

Sampling methods for lice counts are the subject of much debate (Revie et al. 2007, Heuch et al. 2011). When asked about representative sampling, participants raised questions about the sufficiency of counting 10 or 20 fish. Examining this question in more detail, Helgesen \& Kristoffersen (2018) performed 
simulations of lice counting on 20,100, and 200 fish. The authors argued that a single count will only provide a rough estimate of lice numbers at a fish farm. Because lice are not evenly distributed between fish in a net cage, small samples from a total population of up to 200000 will most likely provide an average lice number that differs from the actual lice number in the cage. They concluded that counting more fish than current requirements stipulate may increase the accuracy of the estimate. Related to this, Solberg et al. (2018) stated that the biggest source of uncertainty in current lice counts is related the practical feasibility of counting lice on a larger selection of fish.

Feeding the fish before sampling was common, and one question is whether this practice may lead to samples of primarily hungry fish. Supporting these observations, previous studies evidence that hungry fish often respond in a strong way to feed (Oppedal et al. 2011). However, the connection between hunger and the prevalence of lice on a given fish has not been studied.

The swimming depth of fish was also discussed in the interviews. Fish were usually sampled from a depth of between 5 and $10 \mathrm{~m}$, meaning that the fish below this depth are not included. Oppedal et al. (2011) reported that farmed salmon swim deeper during the day than at night, as they seek favorable temperatures and lighting conditions. Bui et al. (2016) stated that salmon with many lice stay deeper than $4 \mathrm{~m}$ at night, most likely as a way of avoiding higher lice concentrations near the surface. The use of lice skirts, used to prevent lice from entering the fish farm, also affects the depth of salmon (Stien \& Oppedal 2013). The question that remains, however, is whether the sampling depth influences the representativity of the sample.

In the interviews, participants mentioned differences in lice numbers related to the time of day of sampling, but a study by Berntsen et al. (2018) does not support this claim, concluding that the time of sampling did not affect the results. The interviews also highlighted that fish with very poor growth rates are rarely included in the samples. Variation regarding the inclusion of weak fish was found both in the interviews and in the internal procedures of company $\mathrm{C}$. Based on the premise that weak fish are potentially preferred hosts for lice, Solberg et al. (2018) argued that these fish should be included in lice counts to reflect the prevalence of weak fish in a given net cage.

Regarding the findings related to sampling practices, no studies have addressed the potential impli- cations of the sum of the factors described (e.g. counting only 10 fish, not varying the sample depth, and not including any weak fish versus counting a larger sample, varying the sample depth, and including weak fish), thus indicating that this is an area in need of further research.

\subsection{Crowding time and counting salmon lice in sedation containers}

The interviews showed that the equipment used for crowding and the crowding period varied. Three participants said that longer crowding times may lead to a loss of lice as fish come into contact with each other or the net. This aspect was also mentioned in one of the internal procedures of company C. Looking at the effects of crowding time, Berntsen et al. (2018) found few variations in lice counts based on field studies at Norwegian fish farms. In the experiments, farmed salmon were first caught by using a crowding net, and the lice were then counted on a selection of fish after different crowding periods. The applied crowding time in the field studies varied from 2 to $57 \mathrm{~min}$. However, these experiments were not performed with dip nets, which are used by several of the sites included in the interviews presented in this article.

The interviews highlighted that different practices are used to count lice in sedation containers. Using a tarpaulin (white or green) or counting directly in the container and using a filter or sieve were common methods. In a previous study, Gjerde et al. (2016) found that the number of lice in sedation containers varied, especially when the lice were at the mobile stages or were mature female Caligus elongatus. In their experiments, the number of lice in the containers was generally high, and the importance of proper counts was thus emphasized. As practices vary, more research is needed to determine the methods and equipment most suited to capturing and counting lice that fall off the fish and into the container. Solberg et al. (2018) argued that tarpaulins may give better results than counting directly in the container or using filters. If the color of the lice varies from a light brown to a dark brown, then the color of the tarpaulin or container should be light - preferably white.

\subsection{The human factor and objectivity}

The human factor influences objectivity and may have an impact on the representativity of the lice 
counts. Despite formal requirements and internal company procedures for obtaining lice counts, the human factor and certain organizational aspects also have an influence. Comparisons between the interviews and company procedures showed that the procedures do not ensure common practice across fish farms or work shifts. Previous studies argue that noncompliance may be a consequence of employees finding ways to perform the work more efficiently. Employees often look to find the most practical solutions or simply try to get the job done (Størkersen 2012, Thorvaldsen et al. 2015). Whether variations between practices and procedures will influence representativity depends on what the variations are. For instance, the interviews showed that knowing how to distinguish between lice stages varied among employees. This type of variation is related to the quality of training provided to the employees. This, in turn, may influence their objectivity and thus the representativity of the counts.

Increased objectivity that is not influenced by the human factor is one argument for the use of automatization (e.g. using a machine to perform lice counts). In addition to improved precision in detecting and categorizing lice, it is argued that technological solutions will reduce the time and human resources spent counting. The interviews presented in this article showed that the participants acknowledge the potential influence of the human factor. Personal characteristics, subjective assessment, and experience were mentioned. Participants noted the challenges they faced in relation to identifying the species and stages of the lice and acknowledged that conditions such as bad weather or working at night may affect their performance. In a previous study, Gjerde et al. (2016) pointed out that varying environmental conditions, such as light and wind, may affect lice counts. However, they found few or no systematic differences in the number of lice per fish when comparing 3 different counting methods (i.e. counting onboard a work vessel, using a lightbox, or under the light of a luminaire lamp). Another study by Elmoslemany et al. (2013) found that distinguishing between stages and species may be difficult for personnel. Still, Heuch et al. (2011) found no differences when comparing counts from 20 sites performed by both specialized lice-counting teams and employees at fish farms. In a recent study, Berntsen et al. (2018) compared ordinary lice counts from 4 net cages at 2 fish farms with results from a more thorough control count of every 4th fish immediately after the ordinary count. Lice from the control count were also preserved for controlled identification in a lab setting. Overall, the results were almost identical. Very few mature female lice were missed during ordinary counts, and Lepeophtheirus salmonis were rarely miscategorized as C. elongatus. Variations for single fish were found, however. The number of lice were both underestimated and overestimated in ordinary counts. This study suggests that the importance of who does the actual observation and identification of the lice is not a major influencer in terms of objectivity and representativity. However, Berntsen et al. (2018) noted that conditions for counts in these experiments were good, with suitable weather, few lice, and experienced personnel performing the counts - meaning that the influence of these aspects was minimal. The authors also suggested that counts may be affected by a higher prevalence of lice, as this increases the possibility of making mistakes during counting.

The interviews showed that external lice-counting teams are used by 3 companies, and that this practice is not only related to objectivity but also to trust and compliance among companies. Although participants highlighted the challenges related to categorizing lice, interviews also showed that workers may rely on pictures or the help of their colleagues if they were uncertain. Given the findings presented here, as well as the findings of previous studies by Heuch et al. (2011) and Berntsen et al. (2018), the key to ensure correct categorization is to provide employees with sufficient training and the necessary resources to do a good job. To avoid fatigue, good working conditions, such as counting tables that may be adjusted to the height of the workers, may also be useful (Solberg et al. 2018).

\section{CONCLUSIONS}

Current practices for obtaining lice counts at Norwegian fish farms may have implications for representativity related to sampling (e.g. the number of fish), crowding time, and methods for counting lice that land in sedation containers. Furthermore, objectivity in these counts is also related to the human factor and the organization of work (e.g. the knowledge and training of employees who perform the counts). It is important that efforts to reduce the prevalence of salmon lice are based on thorough knowledge of actual practices at fish farms. The regulation of Norwegian aquaculture relies heavily on salmon lice counts as an indicator of sustainability and production growth, and aquaculture companies spend substantial resources on monitoring and prevention of lice and delousing fish. Improved knowledge regard- 
ing the actual practices of obtaining lice counts is therefore valuable for the industry, suppliers to the industry, and its regulators.

In today's regime, the responsibility of conducting a thorough count rests on fish-farm employees. For the aquaculture companies, it is important that companies provide quality training, suitable equipment, and enough resources to ensure that all employees are sufficiently competent to conduct their work in the best way possible. Technology developers must consider how their solutions may influence or improve the representativity and objectivity of lice counts. As lice numbers are essential to the production management regime of Norwegian aquaculture, the implications of today's practices should be addressed for knowledge-based governance that ensures the sustainability of the industry.

Acknowledgements. This article presents findings from the project 'Development of a standardized counting method and calculation of lice occurrence,' which was financed by the Norwegian Seafood Research Fund (FHF) (FHF project no. 901411, SINTEF Ocean project no. 302003565). The authors thank the employees who participated in the interviews, all members of the project team at SINTEF Ocean, the Norwegian Institute for Nature Research, the Norwegian Veterinary Institute, and the industrial reference group for their collaboration and input during the project. We also thank the anonymous reviewers of the manuscript.

\section{LITERATURE CITED}

Abolofia J, Wilen JE, Asche F (2017) The cost of lice: quantifying the impacts of parasitic sea lice on farmed salmon. Mar Resour Econ 32:329-349

Amundsen VS, Osmundsen TC (2018) Sustainability indicators for salmon aquaculture. Data Brief 20:20-29

Anon (2009) Forskrift om bekjempelse av lakselus i akvakulturanlegg (luseforskriften). (Regulation on salmon lice control in aquaculture facilities). Lovdata. https://lovdata. no/dokument/LTI/forskrift/2009-08-18-1095

Anon (2012) Forskrift om bekjempelse av lakselus i akvakulturanlegg. (Regulation on salmon lice control in aquaculture facilities). Lovdata. FOR-2012-12-05-1140. https:// lovdata.no/dokument/SF/forskrift/2012-12-05-1140

Bernard RH (2006) Research methods in anthropology: qualitative and quantitative approaches. Alta Mira Press, Walnut Creek, CA

Berntsen HH, Sivertsgård R, Uglem I, Pettersen O, Frank K, Solberg I, Finstad B (2018) Testing av metodikk for å registrere forekomst av lakselus i oppdrettsanlegg. (Testing of methods for registering the prevalence of salmon lice in fish farms). NINA report 1544. Norwegian Institute for Nature Research, Trondheim

Bui S, Oppedal F, Stien L, Dempster T (2016) Salmon lice infestation levels alters salmon swimming depth in seacages. Aquacult Environ Interact 8:429-435

Dagens Næringsliv (2018) Tidenes strengeste laksedom. (The strictest salmon verdict of all time). https://www.dn.no/ nyheter/naringsliv/2015/10/23/1140/lakselus/tidenesstrengeste-laksedom

* Elmoslemany A, Whyte SK, Revie CW, Hammel KL (2013) Sea lice monitoring on Atlantic salmon farms in New Brunswick, Canada: comparing audit and farm staff counts. J Fish Dis 36:241-247

Finstad B, Bjørn PA (2011) Present status and implications of salmon lice on wild salmonids in Norwegian coastal zones. In: Jones S, Beamish R (eds) Salmon lice: an integrated approach to understanding parasite abundance and distribution. Wiley-Blackwell, Oxford, p 281-305

Føre M, Svendsen E, Alfredsen JA, Uglem I and others (2018) Using acoustic telemetry to monitor the effects of crowding and delousing procedures on farmed Atlantic salmon (Salmo salar). Aquaculture 495:757-765

Forseth T, Barlaup BT, Finstad B, Fiske P and others (2017) The major threats to Atlantic salmon in Norway. ICES J Mar Sci 74:1496-1513

* Gautam R, Vanderstichel R, Boerlage AS, Revie CW, Hammel KL (2017) Effect of timing of count events on estimates of sea lice abundance and interpretation of effectiveness following bath treatments. J Fish Dis 40:367-375

Gjerde B, Lein I, Tanase C (2016) Telling av lakselus. (Counting of salmon lice). Report 34/2016. Nofima, Tromsø

*Hamre LA, Eichner C, Caipang CMA, Dalvin ST and others (2013) The salmon louse Lepeophtheirus salmonis (Copepoda: Caligidae) life cycle has only two chalimus stages. PLOS ONE 8:e73539

Helgesen KO, Kristoffersen AB (2018) Telling av lakselus Hvordan forstå og håndtere usikkerheten i telleresultatene. (Counting of salmon lice - how to understand and handle uncertainties in counting results). Report 222018. Norwegian Veterinary Institute, Oslo

* Hersoug B, Mikkelsen E, Karlsen KM (2019) 'Great expectations' - allocating licenses with special requirements in Norwegian salmon farming. Mar Policy 100:152-162

*Heuch PA, Gettinby G, Revie CW (2011) Counting salmon lice on Atlantic salmon farms - empirical and theoretical observations. Aquaculture 320:149-153

* Jackson D, Moberg O, Stenevik Djupevåg EM, Kane F, Hareide H (2018) The drivers of salmon lice management policies and how best to integrate them into a risk management strategy: an ecosystem approach to salmon lice management. J Fish Dis 41:927-933

Liu Y, Bjelland H (2014) Estimating costs of sea lice control strategy in Norway. Prev Vet Med 117:469-477

O Oppedal F, Dempster T, Stien L (2011) Environmental drivers of Atlantic salmon behaviour in sea-cages: a review. Aquaculture 311:1-18

Revie CW, Gettinby G, Treasurer JW, Wallace C (2005) Evaluating the effect of clustering when monitoring the abundance of salmon lice populations on farmed Atlantic salmon. J Fish Biol 66:773-783

* Revie CW, Hollinger E, Gettinby G, Lees F, Heuch PA (2007) Clustering of parasites within cages on Scottish and Norwegian salmon farms: alternative sampling strategies illustrated using simulation. Prev Vet Med 81:135-147

Solberg I, Finstad B, Berntsen HH, Diserud OH and others (2018) Kartlegging og testing av metodikk for telling av lakselus og beregning av luseforekomst. (Mapping and testing of a method for counting of salmon lice and estimates of lice prevalence). NINA report 1541. Norwegian Institute for Nature Research, Trondheim

Stien LH, Oppedal F (2013) Langtidsvirkning av Perma- 
skjørt på fiskeatferd. (Long term effects of Perma skirts on fish behaviour). Institute of Marine Research, Bergen Størkersen K (2012) Fish first: sharp end decision-making at Norwegian fish farms. Saf Sci 50:2028-2034

Thorvaldsen T, Holmen IM, Moe HK (2015) The escape of fish from Norwegian fish farms: causes, risks and the influence of organizational aspects. Mar Policy 55:33-38

Editorial responsibility: Bengt Finstad,

Trondheim, Norway
Thorvaldsen T, Frank K, Sunde LM (2018) Lusetellingsmetoder i lakseoppdrett En beskrivelse av dagens status. (Lice counting methods in salmon farming: a status description). SINTEF Report No. 2018:00483, Trondheim

*Torrissen O, Jones S, Asche F, Guttormsen A and others (2013) Salmon lice-impact on wild salmonids and salmon aquaculture. J Fish Dis 36:171-194

Submitted: December 18, 2018; Accepted: July 03, 2018 Proofs received from author(s): August 9, 2019 